\title{
International cooperation in the development of national educational programs for quality assessment and measurement
}

\author{
Aigerim Kosherbayeva ${ }^{1 *}$ and Gaziza Kosherbayeva ${ }^{2}$ \\ ${ }^{1}$ Abai Kazakh National Pedagogical University, Almaty, Kazakhstan \\ ${ }^{2}$ University of International Business, Almaty, Kazakhstan
}

\begin{abstract}
The priority direction of modern education around the world is to ensure its high quality, based on the fundamental nature of knowledge and the development of students' creative competencies. Simultaneously, the factors determining new requirements for the assessment and measurement of the quality of education are becoming more obvious and relevant. The setting of such tasks today is aggravated by the processes of globalization, which require collective intelligence, the consolidation of knowledge and world experience, considered as one of the effective ways of developing national educational systems. In this regard, a master's program for measuring and evaluating the quality of education in a network form was implemented with the participation of the Moscow City University and Abai Kazakh National Pedagogical University. It is worthy of highlighting that Kazakhstan needs specialists in the field of education quality assessment and pedagogical measurements. The Institute of System Projects at Moscow City University. has enough experience and is also known to be an expert in this industry. Therefore, an agreement on the exchange of this experience was signed bilaterally. Thus, the master's program has changed the educational process of the main pedagogical university of the country. New aspects of cooperation between the two major universities have been opened.
\end{abstract}

Keywords: assessment, activities, students, education.

\section{Introduction}

In the last decade, citizen-led evaluations have been developed in different countries in Asia and Africa. These evaluations are innovative, given that they provide sources of information that complement governmental assessments and promote social participation in education [1, 2]. The main characteristic of mankind in the XXI century is self-development, spiritual renewal. All changes in development are always made by human beings. Mankind's actions are unique, as evidenced by the ability to actively engage in dialogue at the level of empathy, contribution, partnership, and cooperation [3-5].

The dialogue within the framework of the upcoming cooperation began back in 2017 and a year later the program was launched. In Abai KazNPU, it was implemented in the period

* Corresponding author: aigera63@mail.ru 
of 2018-2020 academic year at the Institute of Pedagogy and Psychology as "Pedagogical measurements". Interest in the program is growing every year thanks to its network implementation, and at the moment there have been enrollments of master's students until 2022. The training of masters takes place in 3 languages: Kazakh, Russian and English, taking into account the specifics of training courses.

The main issue in the implementation of the bilateral program is the process of coordinating the content of education. All the features of training the Kazakh side were taken into account in two ways. Simultaneously, the value of the networked program was in the integration of such subjects as "Developmental Assessment of the Quality of School Education (SAM)" [6,7] into the university component; Assessment of Educational Conditions: SACERS [8]; "Assessment of educational conditions: ECERS" [9, 10] and others, developed by specialists from the Institute of System Projects at Moscow City University (MCU).

\section{Methods}

We conducted a survey among second-year master students who are majoring in the subject' pedagogical measurements' at Abai KazNPU in order to highlight the significance of assessment of knowledge level. Participants are also part-time teachers in the local schools and they have been asked to give their opinion based on their experience. The question was if the assessment is fair.

Student 1: As for the question of whether the assessment and evaluation in the education system are fair, I would say that it is fair. Because without assessment, the learning process would lose its meaning. However, the concept of evaluation is only fair if it is used as a result, but sometimes the evaluation process is set as a goal. Therefore, it depends on the teacher's opinion and position on the concept of assessment and evaluation. Firstly, if a student is not assessed during the lesson, it will be difficult to know how well he/she understands and masters the given knowledge.

Student 2: Assessment in the general education system has a great impact on the development of motivation, attention, goal-orientation in the students. Assessment plays a key role that leads to improving the quality of knowledge. That is, if we compare all educational institutions, we can see that there is injustice in the assessment. There are various reasons for the injustice in the assessment of the knowledge, in particular: low grades are given for the bad behavior of a very knowledgeable student; there are times when a student achieves high results in only one area.

Having analyzed students' opinions about the assessment system in Kazakhstan, we found out there are still gaps in the evaluation of acquired knowledge due to some factors such as the status of the educational institutions, future interests of students, or lack of a proper assessment system.

\section{Results}

Modern management concepts are externally presented in Russian education and in other areas of management discourse and practice. In particular, in additional or global education it is extremely important to know its subject, object, purpose, and objectives, etc. Otherwise, as in the case of state educational institutions, imitations will arise that are more likely to harm education and society than support it [11]. That is why it is important to master the program that also makes it possible to participate in project research, to attract undergraduates to scientific research within the framework of projects of the Institute of System Projects of 
MCU and the Institute of Pedagogy and Psychology of Abai KazNPU. Thus, within the framework of joint educational activities, the following activities were carried out:

1. Modular educational programs and working curricula of the Department of Pedagogy and Psychology have been agreed with the Institute of System Projects (June 2018);

2. Methodological seminars-meetings of scientists from universities were organized to improve the program at Abai KazNPU in Almaty between 2018 and 2019;

3. Training seminars by MCU specialists in preschool organizations and schools in Kazakhstan in April and October 2018, and also in November 2019;

4. Republican pedagogical olympiads for undergraduates with the participation of partners and counseling on master's theses by specialists from MCU;

Presenting of the project at the First Annual International Symposium "Education and Megapolis: Partnership for Sustainable Success" (Moscow, 2018) and the annual conference of Eurasian Association for Education Quality Assessment "Assessment of quality at different levels of education" (Dushanbe, 2018).

\section{Discussion}

Nowadays, practice shows that the curriculum of the program allows graduate students to form a holistic model of activity in the design and management of systems for assessing and monitoring the quality of education in educational institutions. The studied disciplines provide the study of all the necessary areas of knowledge for the formation of the skills of a specialist capable of developing and implementing systems for assessing the quality of education, conducting and analyzing procedures for monitoring and assessing the quality of education in an educational organization.

Assessment is not only related to evaluating the students' knowledge. It also evaluates teacher ability and performance. This includes documenting the quality of the teacher's work; the focus then shifts to helping teachers improve their academic performance and holding them accountable for their work [12]. Assessment plays a key role in the education system. There are different interesting studies on assessment and evaluation [13]. One research conducted in the Nursery Degree Programme of Bologna University. The results confirm a certain relevance of thinking about the level of proficiency in student learning strategies over the past 20 years: in fact, the assessments of university students are now not so far from students' learning outcomes at the age of 15 years in 1996 [14]. Another research on evaluation of the National Assessment of Educational Progress provides a number of recommendations for addressing validity concerns. It identifies actions that could be taken for improving validity of assessment in responding to those concerns [15]. It means that educational assessment system in general is faced with the certain challenges and need well trained professionals at all levels.

\section{Conclusion}

In summary, the task of improving the quality of academic performance and knowledge is considered as one of the keys. Consequently, there is a growing need for the development and development of measuring instruments, the creation of effective methods for assessing quality, and the logical appeal to international experience. In Kazakhstan, it is possible to ensure the quality of assessment procedures and their compliance with international standards. This can be achieved by establishing clear and measurable assessment. The master program created in collaboration of Abai KazNPU and MCU is an important contribution to the development of the educational assessment system in Kazakhstan. 


\section{References}

1. F.J. Hevia, S.V.T. Tristan, Innovacion educativa-mexico, 16(70), 85-109 (2016)

2. M.R. Arpentieva, G.K. Kassymova, S.V. Lavrinenko, Z.I. Tyumaseva, G.V. Valeeva, O.B. Kenzhaliyev, M.B. Triyono, O.N. Duvalina, A.V. Kosov, S.K. Dossay, Bulletin of National Academy of Sciences of the Republic of Kazakhstan, 3(379), 11-18 (2019). https://doi.org/10.32014/2019.2518-1467.82

3. Z. Bissenbayeva, K. Aigerim, T. Zinagul, N. Zhanar, Procedia - Social and Behavioral Sciences, 89, 872-875 (2013). https://doi.org/10.1016/j.sbspro.2013.08.947

4. A. Kosherbayeva, K. Abdreimova, G. Kosherba, A. Anuarbek, Procedia - Social and Behavioral Sciences, 89, 886-889 (2013). https://doi.org/10.1016/j.sbspro.2013.08.950

5. A.A. Badalov, S.N. Brovkina, M.R. Arpent'yeva, S.S. Kalinin, G.K. Kassymova, Clinical Psychology and Special Education, 9(1), 1-16 (2020). https://doi.org/10.17759/cpse.2020090101

6. P. Nezhnov, E. Kardanova, M. Vasilyeva, L. Ludlow, Educational and Psychological Measurement, 75(2), 235-259 (2014). https://doi.org/10.1177/0013164414534068

7. P. Nezhnov, CADMO, 19(1), 85-98 (2011). https://doi.org/10.3280/CAD2011-001010

8. E.V. Ivanova, I.A. Vinogradova, European Journal of Contemporary Education, 7(3), 498-510 (2018). https://doi.org/10.13187/ejced.2018.3.498

9. D. Cryer, C. Riley, T. Link, All About the ECERS-3 (Kaplan, 2020)

10. S. Sheridan, O. Shiyan, I. Shiyan, Preschool quality and conditions of children's learning in preschool in Russia and Sweden: Russian and Western Values, in Vygotsky's Theory in Early Childhood Education and Research, 193-205 (Routledge, Philadelphia, 2018)

11. S.V. Lavrinenko, I.V. Gorelova, K.G. Kassymova, O.V. Kubantseva, T.L. Khudyakova, I V. Yusipova, D.M. Malinichev, L.B. Dykhan, G.A. Stepanova, M.R. Arpentieva, Bulletin of the National Academy of Sciences of the Republic of Kazakhstan, 1, 264-276 (2020). https://doi.org/10.32014/2020.2518-1467.32

12. J.H. Stronge, Educ Asse Eval Acc, 25, 155-158 (2013). https://doi.org/10.1007/s11092-013-9172-z

13. K. Edge, Educ Asse Eval Acc, 24, 173-174 (2012). https://doi.org/10.1007/s11092012-9151-9

14. E. Luppi, S. Benini, Journal of educational cultural and psychological studies, 16, 99127 (2017). https://doi.org/10.7358/ecps-2017-016-lupp

15. J. Noell, A. Ginsburg, Applied Measurement in Education, 22(4), 409-414 (2009). https://doi.org/10.1080/08957340903221691 